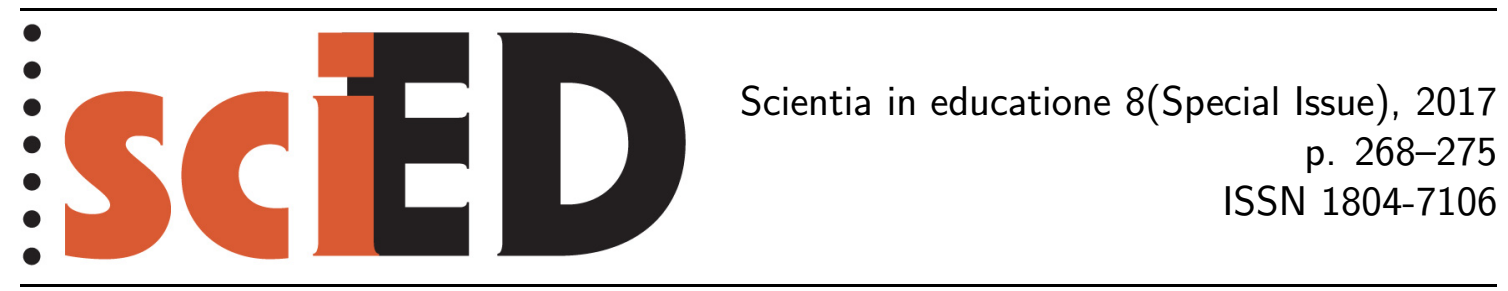

\title{
Learn from History: Lessons from Early Modern Japanese Physics Experiment Textbooks
}

\author{
Hiroshi Takahashi, Akira Akabane, Jun Shozawa, Toyomi Tamaki
}

\begin{abstract}
The aim of our study is to explore the early history of the education of physics experiments in the Meiji era of Japan (1868-1912). In this paper, we examine three Japanese physics experiment textbooks which were published during 1880s. One characteristic feature is that the most of the experiments could be performed using simple handmade apparatuses. We consider what can be learned from the ingenuity of physics education pioneers of the late $19^{\text {th }}$ century.
\end{abstract}

Key words: physics experiment, Meiji era, handmade, simple experiment, history of physics education. 


\section{INTRODUCTION}

The island nation of Japan had adhered to a closed-door policy to the outside world between 1639 and 1854. During this period, Japan traded only with China and the Dutch through restricted ports. As a result, very little knowledge of modern Western science reached Japan by means of Chinese and Dutch books. From the inception of the Meiji Restoration in 1868, leaders of the nascent Meiji government recognized that science and technology were essential to the development of new industry. Consequently, the full-scale influx of modern Western science was encouraged. The general public also felt that, learning rational thinking of the West would be required for the country's modernization. It is within this context that a publication boom of physics textbooks occurred and present-days historians refer to it as kyuri-netsu (literally, enthusiasm for physics) (The Physical Society of Japan, 1978). Itakura (2009) reported that $c a$. 40 general science books that primarily cover physics were published in 1872-1873. One of the leading educational figures of his time, Yukichi Fukuzawa (1835-1901), eagerly disseminated the new idea of rational thinking. His work, Kunmo Kyuri Zukai (Illustrated Introductory Physics) (Fukuzawa, 1868), first published in 1868, is regarded as the trigger of the publication boom in the early Meiji era.

The Japanese school educational system modelled after the West began when the Education System Order (Gakusei) was promulgated in August, 1872. The elementary school curriculum was regulated according to the Elementary School Curriculum (Shogaku Kyosoku) established in the following month, and in which five subjects related to science appeared, i.e., Regimen, Natural Philosophy, Natural History, Chemistry, and Physiology (yojo-kujo, kyurigaku-rinko, hakubutsu, kagaku, and seiri, respectively). The entire curriculum was expected to be completed in eight years. The main scientific subjects, natural history, chemistry, and physiology were taught on the seventh and eighth grades. In practice, however, as Itakura (2009) revealed, the majority Japanese elementary schools of the 1870s, there were actually relatively few students in the higher grades where science was taught. After 1880, the number of students there began to increase and as a result, science education at the elementary level began in earnest. This situation brought about an earnest discussion on how to best perform physics experiments in the classroom. Domestic leaders of science education had recognized the importance of performing experiments and consequently, no less than ten physics experiment textbooks in Japanese were published successively during the four-year span of 1882-1886, as Nagata (1994) has shown.

In order to explore the early history of physics experiments education in Meijiera Japan, here, we analyze several representative textbooks among these textbooks. In particular, we will deal with three textbooks. The first is Rika-Shoshi (Simple and Easy Experiments of Physics and Chemistry) (1882), a translation of an American textbook but notable for being the first physics experiment textbook written in Japanese. The second is Kan'i-Shiken-Ho (Simple Experiments) (Udagawa, 1885) written by Jun'ichi Udagawa (1848-1913). The latter textbook is not a translation, but rather the first original Japanese physics experiment manual. The third textbook is Kan'i Kikai Rikagaku Shiken-Ho (Physics and Chemistry Experiments using Simple Apparatuses) (Goto \& Miyake, 1886), written by Makita Goto (1853-1930), who is recognized as the most influential figure of Meiji-era physics education. Udagawa is considered a leader of the first generation of educators in physics, and Goto is a leader of the second generation. The outstanding feature of these three text- 


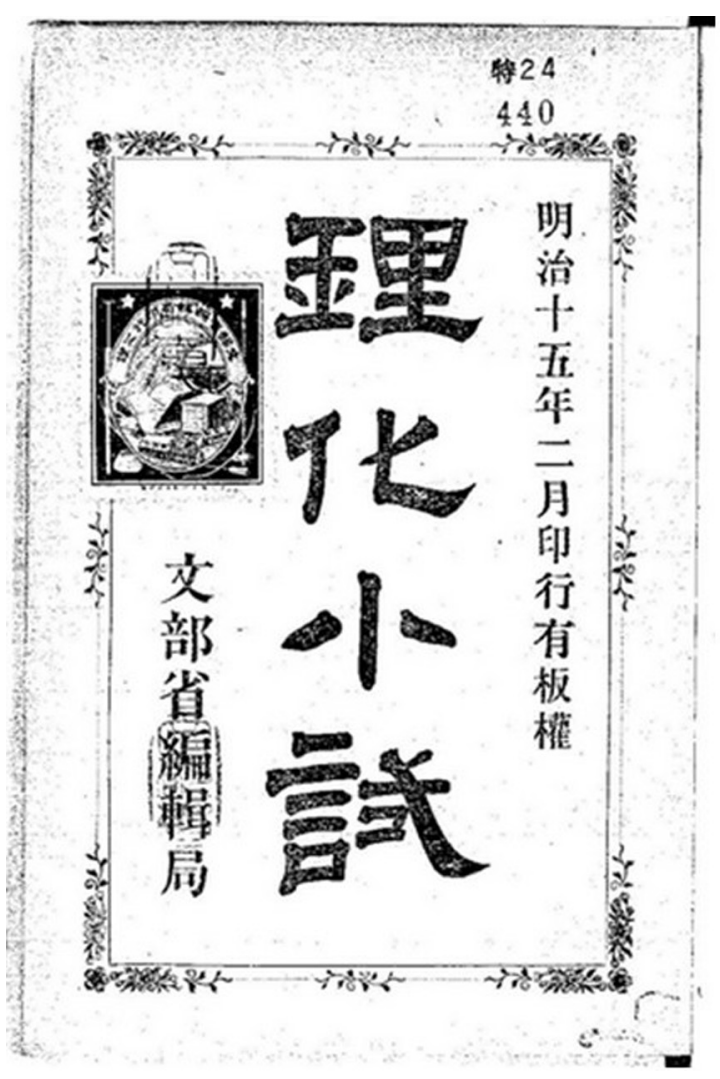

a)

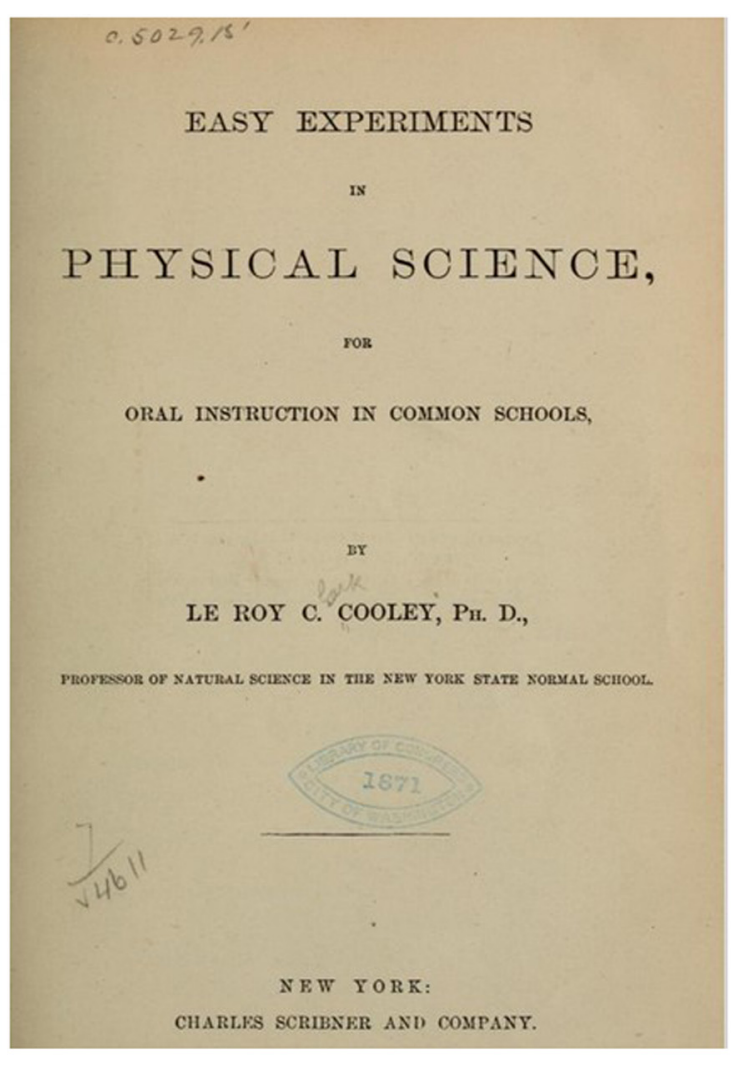

b)

Figure 1: a) The title page of Rika-Shoshi (1882), b) The title page of Easy Experiments in Physical Science by Le Roy C. Cooley (1870)

books is that the most of experiments can be performed with low-cost, everyday materials.

\section{First Japanese Physics Experiment Textbook, Rika-Shoshi}

The first Japanese textbook on physics laboratory teaching is Rika-Shoshi (Figure 1a)) that was published by Monbusho (the Ministry of Education) in 1882. This textbook was translation of Easy Experiments in Physical Science (Figure 1b)) by Le Roy C. Cooley (1833-1916) and published in 1870 by Charles Scribner and Company of New York. The translator of the textbook, Ten Maomura (1853-?), worked at the Tokyo Educational Museum (present-day Tokyo National Museum) when the textbook was published. The original Japanese is the same as the original, which contains 178 experiments, of which 145 are for physics and the remaining 33 for chemistry. As mentioned above, the experiments could be performed by using low-cost apparatus or everyday materials.

Needless to say, during Meiji ear, there were vast differences in lifestyle and culture between the East and West. Thus, for Japanese to obtain the same materials was extremely difficult. Consequently, the Japanese version, Rika-Shoshi, contains some explanatory notes. For example, the explanatory note in Rika-Shoshi recommend using beniko, a fine Japanese red powder used in make-up, for coloration as a substitute for of cochineal extract powder. In addition, other explanatory notes 
called for modifications to the experiments themselves (see Takahashi et al., 2014 for details).

As we have covered the personal history of Jun'ichi Udagawa (1848-1913), the editor of Rika-Shoshi elsewhere (Takahashi et al., 2014), we would like to turn to Le Roy C. Cooley (1833-1916), as described in An Historical Sketch of the State Normal College at Albany (New York State University, 1894). A graduate of Union College in 1858, Cooley taught mathematics at the Fairfield Academy and Cooperstown Seminar. From 1861, he was appointed professor of Natural Science at the New York State Normal College in Albany. In 1874, he moved to Vassar College, one of oldest colleges for women in the United States. There, he became the first professor of physics, his Ph.D. having been conferred by Union University four years earlier.

One of his most notable review papers was The Molecular Theory published in Popular Science Monthly (Volume 15, August 1879) (Cooley, 1879). An anonymous reviewer (Book review, 1880) of Cooley's The New Text-Book of Physics (1880) wrote, "Professor Cooley was among the first to attempt to introduce into elementary instruction in physics the modern doctrine of molecules and molecular action". In fact, Easy Experiments in Physical Science was written consistently on the basis of molecular theory. Itakura published a reproduction of Rika-Shoshi in 1972. In his postscript of the reproduction, Itakura (1972) wrote, "reading Rika-Shoshi makes me overjoyed because I found that that early Meiji-era scientific concepts are based on the modern view of matter supported by molecular theory." Itakura have insisted that molecular theory should be taught even at elementary school levels (Itakura, 2009). Indeed, it is probable that Rika-Shoshi played an essential role in spreading the concept of molecular theory in Meiji-era Japan.

As expected from the full title of Easy Experiments in Physical Science, for oral instruction in common schools, the textbook is not only a teaching manual of physics experiments but also an instructs teachers how to adequately pose questions to students during the experiments. In fact, Cooley wrote "While making an experiment the teacher ought, by skilful questions and appropriate remarks, to keep the attention of the children upon it, so that every part of the apparatus shall be observed and every action definitely seen. Above all things ought to care to be taken that the final inference is seen to be the natural consequence of the facts observed in the experiments."

\section{First Japanese Original Physics Experiment Textbook, Kan'i-Shiken-Ho}

The editor of Rika-Shoshi textbook was Jun'ichi Udagawa, a physics teacher of the Gunma Normal School (now, Gunma University). According to university archives, Udagawa performed some experiments with handmade apparatuses in his physics lectures of 1884. He published the first Japanese original physics experiment textbook, Kan'i-Shiken-Ho (Simple Experiments) at the following years. In it, Udagawa explained how experiments in his previously published textbook, Butsuri-Shoshi (Short Course of Physics) could be performed by using mainly everyday materials: "When we have no flask, we should use an ordinal bottle of false bottom", or, "when no magnetic needle is available, the use of a sewing needle is recommended". A sewing needle can be easily magnetized by rubbing it with a magnet. When the 
magnetized sewing needle is rotated freely by suspending it with a thin silk thread, the needle will rotate to the direction of north-south axis.

Physics had become established in the school curriculum at that time. In the preface of Kan'i-Shiken-Ho, Udagawa describes his motive for authoring the textbook: "Physics is an indispensable subject in the elementary school curriculum, as evident by the recent Guidelines for the Course of Study for Elementary Schools (Shogaku Kyosoku Koryo, 1881), thus, I published Butsuri-Shoshi (Short Course of Physics)." But Udagawa fully realized the limitations of Japanese schools at that time, saying, "Because physics is based on substance, the laws and principles of physics should be explained through physical experiments. However, local governments are severe financial straits, e.g., and in most mountain villages, it is extremely difficult to obtain satisfactory experimental instruments. Therefore, I wrote this textbook." Although the Gunma Normal School had proper equipment to perform demonstration experiments at that time (Takahashi et al., 2014). Udagawa preferred to use handmade instruments in his classes. We can interpret such actions that Udagawa thought that when his students became teachers and were placed at a poor rural school, they could make do with common everyday materials.

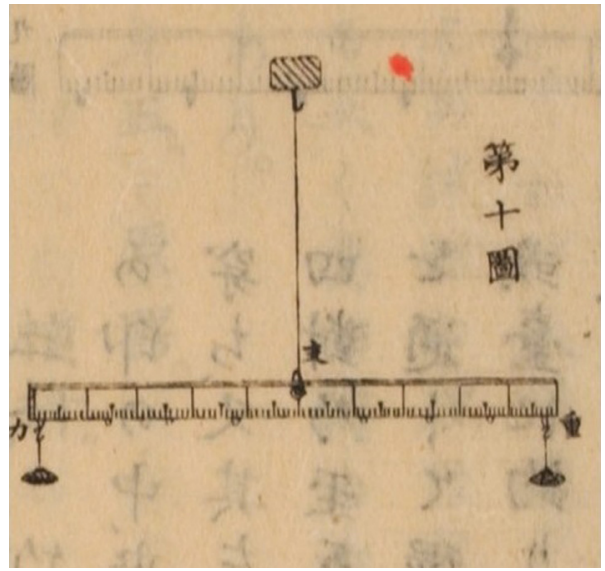

Figure 2: Balance made from a Bamboo Scale

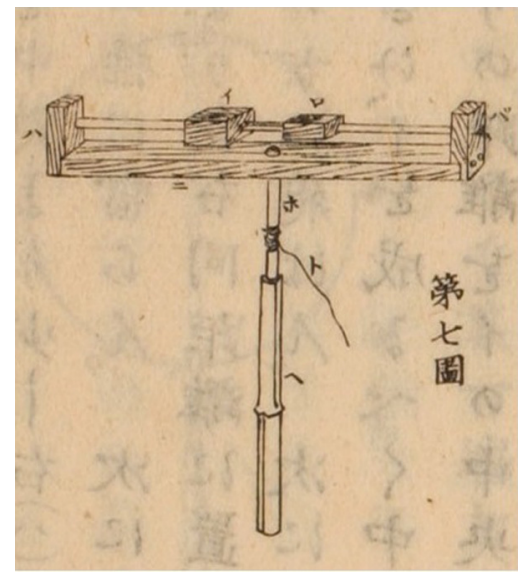

Figure 3: Bamboo apparatus for showing centrifugal force

\section{Makita Goto And His Simple Experiment TEXTBOOK}

If Jun'ichi Udagawa belonged to the first generation of Japanese physics educators, Makita Goto was a leader in the second generation. Udagawa resigned from the Gunma Normal school in 1885. He then went to work at Imperial Japanese Army General Staff Office, where he taught surveying and photographic techniques for cartography (Sugiyama, 1911). Udagawa never returned to teach physics at school and he disappeared from the world of physics education after his resignation from the Gunma Normal School. In Udagawa's footsteps, Makita Goto became a leader of physics education. Five years younger than Udagawa, Goto taught physics at the Tokyo Normal School (now Tsukuba University) from 1877 to 1914. During his tenure, he had taught the next generation of Japanese physics teachers.

Goto authored a large number of physics textbooks, usually co-authored with his disciples. Goto's first experiment textbook, Kan'i Kikai Rikagaku Shiken-Ho Kan- 
Ichi (Simple Physics and Chemistry Experiments Using Homemade Apparatuses, No. 1) was co-authored by Yonekichi Miyake (1860-1929), and published in 1885. The title of "No. 1" would seem to indicate a series but no subsequent publication appeared. Although the title indicates that chemistry experiments are included, most of the experiments of the textbook are in physics. It could be that the next book in the series would describe mainly chemistry experiments.

Although not exclusive to Kan'i Kikai Rikagaku Shiken-Ho Kan-Ichi, typical of Goto's work is that many of the experimental apparatuses are made from wood or bamboo. Figure 2 shows a balance made from a bamboo scale. To explain centrifugal force, Goto devised an apparatus (shown in Figure 3) that when rotated, two wooden pieces, supported by thin metal wires but are freely movable, move to both ends due to centrifugal force. Many physics textbooks published in Europe and America in the late $19^{\text {th }}$ century, explain the mechanism of lifting-Pump using an illustration as in Figure 4. The lifting-Pump which appears in Kan'i Kikai Rikagaku Shiken-Ho Kan-Ichi is made from bamboo tubes (Figure 5).

Most of the architecture in Europe and North America employs inorganic materials such as stones and bricks. In contrast, traditional Japanese architectures such as Buddhist temples, Shinto shrines, are made mainly of wood. It is only natural then, that Japanese physics textbooks would employ traditional building materials such as those found in Goto's work.

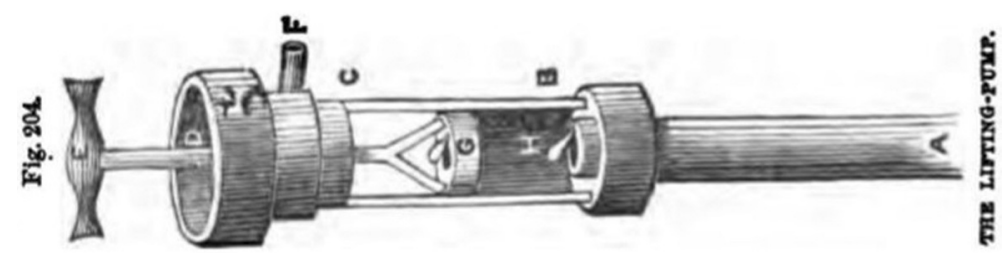

Figure 4: Lifting-pump. This figure is taken from A Natural Philosophy by G.P. Quackenbos (1869)

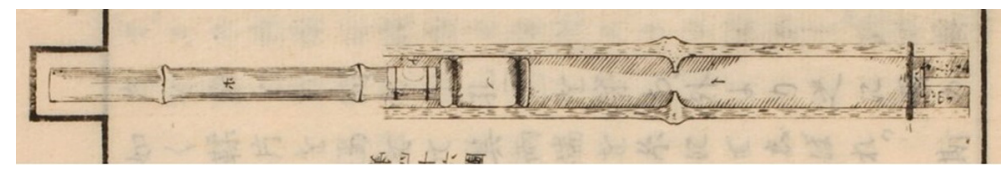

Figure 5: Balance made from a Bamboo

\section{Conclusions}

Under the Elementary School Curriculum (Shogaku Kyosoku) of 1872, Japanese educational authorities insisted that experiment be performed in science lessons (Nagata, 2003). However, the central government did not usually bear the cost of elementary and secondary schools, rather but the local villages, towns, and prefectures did. Of course, the financial health of local governments varied widely and it certainly was quite difficult for many schools to obtain a full set of ready-made experimental instruments. Given these circumstance, it would be entirely appropriate for the Ministry of Education to publish a translation of Easy Experiments in Physical Science as the first physics experiment textbook for elementary schools. The majority of its experiments can be performed using low-cost everyday materials. In 
spite of the vast differences in culture and lifestyle, because they had a good understanding of handmade physics experiments developed in Europe or North America, early modern Japanese physics educators successfully modified the same experiments with a dash of local ingenuity, especially traditional wood-working.

So, what can be learned from this discussion of early physics experiment textbook in the late $19^{\text {th }}$ century? The same would apply today if one were to use teaching materials developed by other people in a different context. The most important thing is not to get funding and introduce only the newest and latest teaching materials. It is imperative for educators to consider which improvements or adaptations are required to optimize the materials for their own context. There is no denying that some money is necessary to prepare an experimental apparatus and virtual experiments simulated on a computer can reduce expenses. We would so well to bear in mind Udagawa's preface to Kan'i-Shiken-Ho, "physics is based on substance". and that touching and operating real substances are indispensable to understanding the physical world. Handmade and inexpensive experimental apparatuses similar to those developed in the late $19^{\text {th }}$ century could be used in present-day classrooms, if one were to add the appropriate modifications.

\section{ACKNOWLEDGEMENT}

We would like to acknowledge and thank the staff of the Gunma University Library for their effort in preserving the archives. We would also like to thank Professor Barry Keith (Gunma University) for his English revision of the manuscript. This work was supported by JSPS KAKENHI Grant Numbers 25282043 and 19500779.

\section{REFERENCES}

Book review. (1880). The Popular Science Monthly, 18(11), 135-136. Available at http://archive.org/details/popularsciencemo18newy

Cooley, L. C. (1870). Easy experiments in physical science, for oral instruction in common schools. C. Scribner and Company. Available at http://archive.org/details/easyexperiments00cool

Cooley, L. C. (1879). The molecular theory. The Popular Science Monthly, 15(8), 462-470. Available at http://archive.org/details/popularsciencemo15newy

Cooley, L. C. (1880). The new text-book of physics. New York: Charles Scribner's Sons. Available at http://archive.org/details/newtextbookofphy00coolrich

Fukuzawa, Y. (1868). Kunmo Kyuri Zukai (Illustrated introductory physics). Keio-Gijuku. Available at http://kindai.ndl.go.jp/info:ndljp/pid/830074

Goto, M. \& Miyake, Y. (1886). Kan'i Kikai Rikagaku Shiken-Ho Kan-Ichi (Simple physics and chemistry experiments using homemade apparatuses, No. 1). Fukyu-Sha.

Itakura, K. (1972). Postscript in the reproduction of Rika-Shoshi. Kasetsu-Sha.

Itakura, K. (2009). Zoho Nihon Rika Kyoiku-Shi (Japanese history of science education, revised and enlarged edition). Kasetsu-Sha.

Nagata, A. (1994). Nihon Rika Kyouzai-Shi (The history of Japanese general science teaching materials). Tokyo Horei Publishing. 
Nagata, A. (2003). Shi-Rika-Kyoiku-Nyumon (New introduction on general science education). Hoshi-No-Wano-Kai.

New York State University, Albany. (1894). An historical sketch of the State Normal College at Albany, N.Y. and a history of its graduates for fifty years, 1844-1894. Albany: Brandow Print Company. Available at http://archive.org/details/historicalsketch01newy

Sugiyama, K. (1911). Okayama-Ken-Meikan (The Directory of Okayama Prefecture).

The Physical Society of Japan. (1978). Nihon No Butsurigaku-Shi (Japanese history of physics). Tokai University Press.

Quackenbos, G.P. (1869). A natural philosophy. New York: D. Appleton and Company. Available at http://archive.org/details/anaturalphiloso06quacgoog

Rika-Shoshi (Simple and easy experiments of physics and chemistry). (1882). Monbusho. Available at http://kindai.ndl.go.jp/info:ndljp/pid/826131

Takahashi, H., Akabane, A., Shozawa, J. \& Tamaki, T. (2014). Rika-Shoshi, the first physics experiment textbook published in Japanese and its editor, Jun'ichi Udagawa. JPS Conf. Proc. 1, 017023 . Available at http://journals.jps.jp/doi/abs/10.7566/JPSCP.1.017023

Udagawa, J. (1885). Kan'i-Shiken-Ho (Simple experiments). Bungaku-Sha. Available at http://kindai.ndl.go.jp/info:ndljp/pid/830422

HIROSHI TAKAHASHI

Faculty of Science and Technology, Gunma University, Maebashi, Japan

Akira Akabane

Saitama Medical University, Saitama, Japan

Jun Shozawa

Tokyo Future University, Tokyo, Japan

TOYOMI TAMAKI

Mathematical Assist Design Laboratory, Maebashi, Japan 